\title{
GRAPHITE TO GRAPHENE VIA GRAPHENE OXIDE: OVERVIEW ON SYNTHESIS, PROPERTIES, AND APPLICATIONS
}

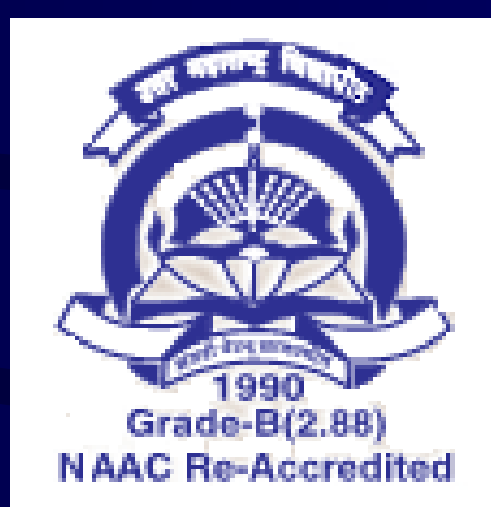

Satyendra Mishra*, Navinchandra G. Shimpi, Dharmesh P. Hansora University Institute of Chemical Technology North Maharashtra University, Jalgaon-425001 Maharashtra, India *profsm@rediffmail.com

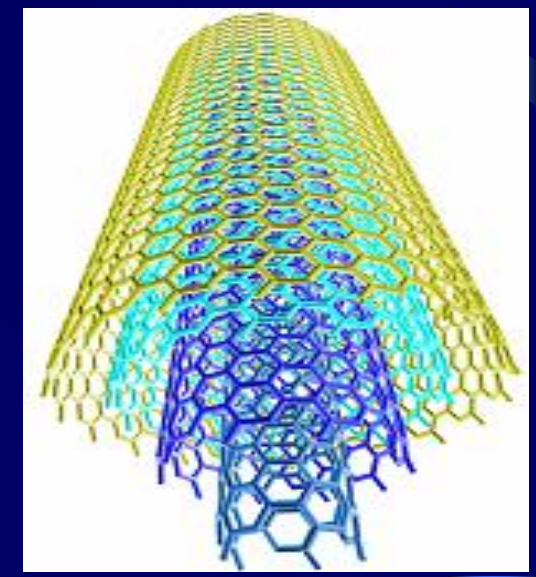




\section{Objectives}

- To discuss the most recent progress on graphene-related nanomaterials, including doped graphene and derived graphene nanoribbons, graphene oxide, graphane, fluorographene, graphyne, graphdiyne, and porous graphene, from both experimental and theoretical perspectives.

- To overview briefly of the synthesis, properties, and applications of graphene and related materials and emphasize tuning their stability, electronic and magnetic properties by chemical functionalization.

- To discuss synthesis and characterization of graphene oxide, graphene sheets from graphite using new continuous running underwater arc-discharge technique. 


\section{Introduction}

- Up to 1980s:

Carbon Materials are

$\checkmark$ Diamond

$\checkmark$ Graphite

- Since 1980s:

Carbon Materials are

$\checkmark$ Fullerence (Bucky balls)

$\checkmark$ Carbon Fibers
- Now a days:

Carbon Materials are

$\checkmark$ Carbon Nanotubes

$\checkmark$ Graphene sheets

$\checkmark$ Graphene derivatives

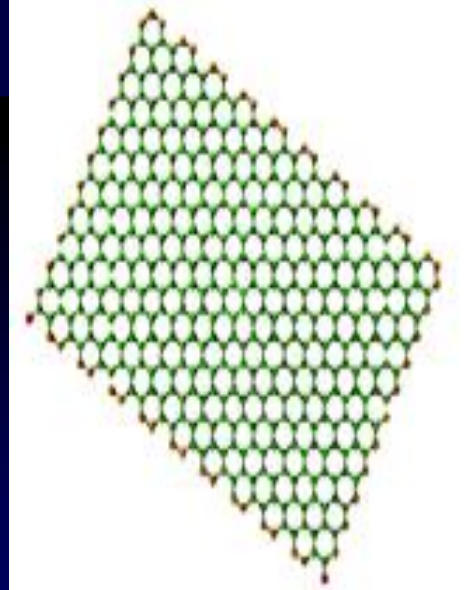

Single layered graphene sheet

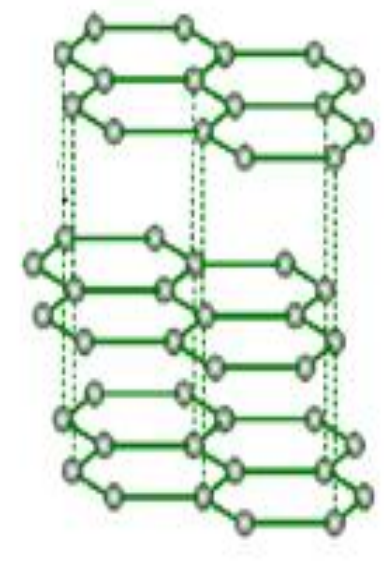

Graphitic structure

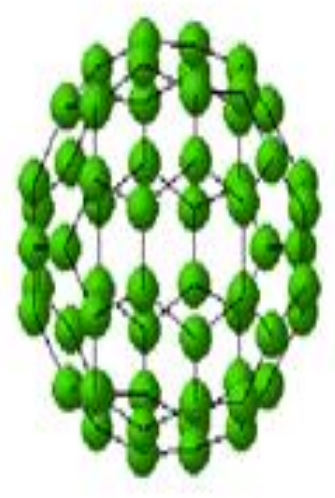

Bucky Ball $\mathrm{C}_{60}$
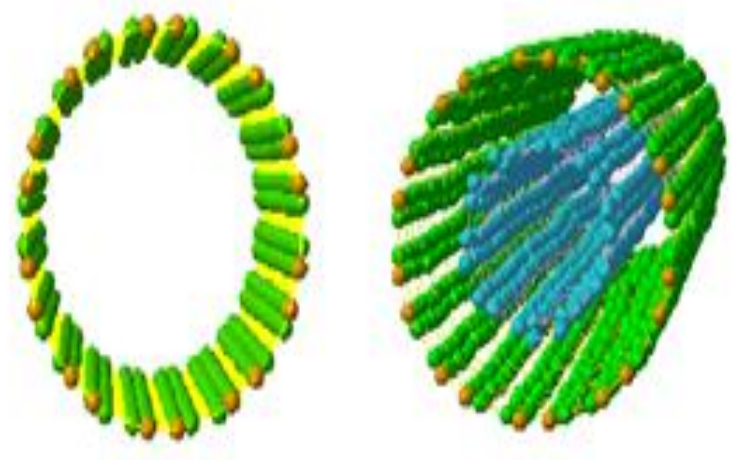

DWCNT

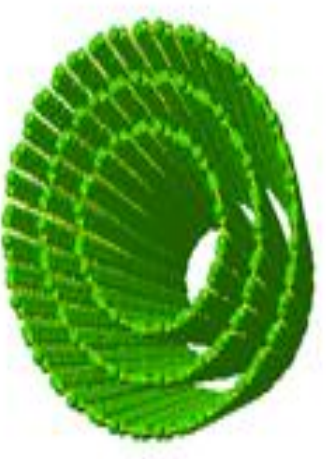

MWCNT 


\section{Introduction}

- Graphene is the basic structural unit of some carbon allotropes, including graphite, carbon nanotubes (CNT) and fullerenes composed of benzene rings stripped of their hydrogen atoms.

- The rolling up of graphene along a given direction can produce a CNT.

- A zero-dimensional fullerene can also be obtained by wrapping-up graphene.

"When carbon fibres just won't do, but nanotubes are too expensive, where a cost-conscious materials scientist can go to find a practical conductive composite?

The answer could lie with graphene sheets"

- Graphene is considered a 2D carbon nanofiller with a one-atom-thick planar sheet of $\mathrm{sp}^{2}$ bonded carbon atoms that are densely packed in a honeycomb crystal lattice.

- It is regarded as the "thinnest material in the universe" with tremendous application potential. 


\section{Introduction}

Graphene-related carbon materials

(1) Graphene nanoribbons (GNRs) (5) Graphyne and graphdiyne

(2) Graphene oxide (GO)

(3) Graphane

(4) Fluorographene

(6) Porous graphene

(7) Graphone

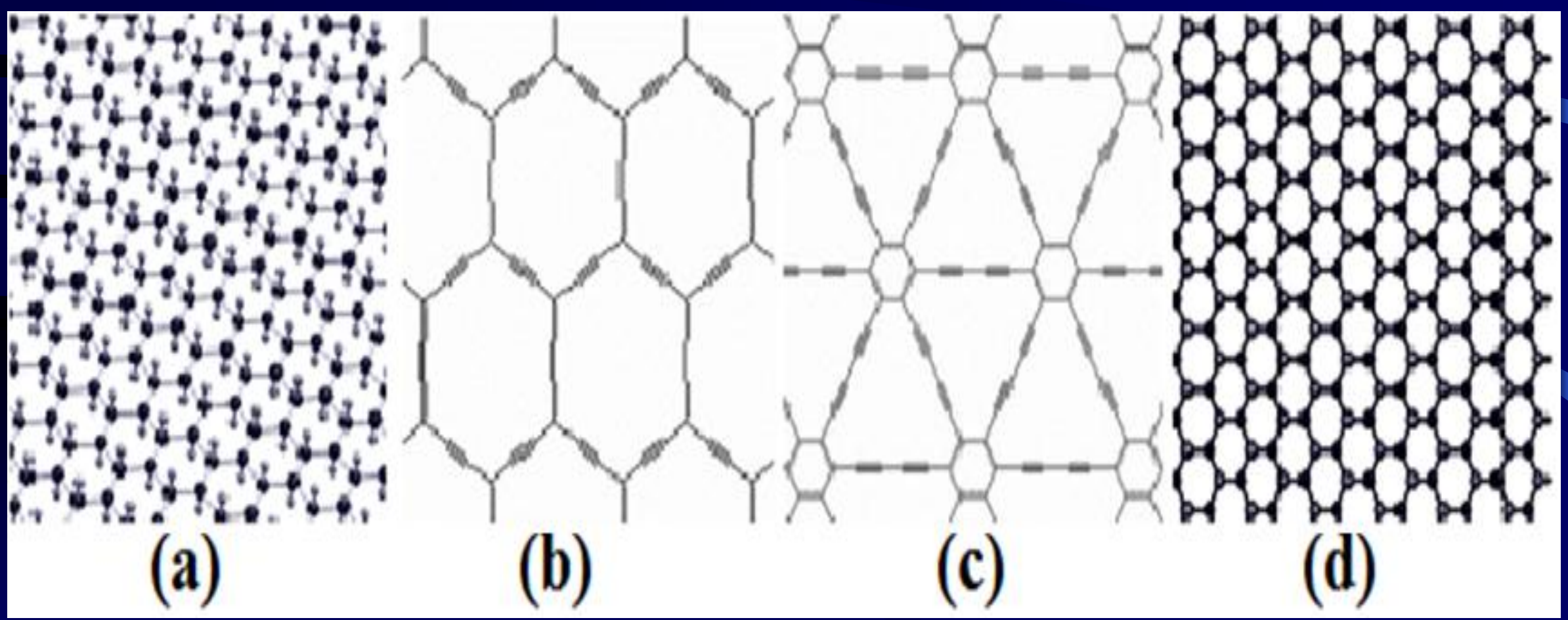

Structure of (a) graphane, (b) graphyne, (c) graphdiyne and (d) graphone

Peng Q, Dearden AK, Crean J, Han L, Liu S, Wen X, De S 2014 New materials graphyne, graphdiyne, graphone, and graphane: review of properties, synthesis, and application in nanotechnology Nanotechnology, Science and Applications 7 pp 1-29 


\section{Properties}

(1) Morphological and structure

(2) Electronic

(3) Mechanical

(4) Optical

(5) Thermal
(6) Magnetic

(7) Electrochemical

(8) Electrical

(9) Surface

Properties of graphene, CNT, nano sized steel, and polymers

\begin{tabular}{|c|c|c|c|}
\hline Materials & Tensile strength & $\begin{array}{l}\text { Thermal conductivity }(\mathrm{W} / \mathrm{mK}) \\
\text { at room temperature }\end{array}$ & Electrical conductivity (S/m) \\
\hline Graphene & $130 \pm 10 \mathrm{GPa}$ & $\begin{array}{ll}(4.84 \pm 0.44) \times 10^{3} & \text { to } \\
(5.30 \pm 0.48) \times 10^{3} & \end{array}$ & 7200 \\
\hline CNT & $60-150 \mathrm{GPa}$ & 3500 & $3000-4000$ \\
\hline Nano sized steel & $1769 \mathrm{MPa}$ & $5-6$ & $1.35 \times 10^{6}$ \\
\hline Plastic (HDPE) & $18-20 \mathrm{MPa}$ & $0.46-0.52$ & Insulator \\
\hline $\begin{array}{l}\text { Rubber } \\
\text { (natural rubber) }\end{array}$ & 20-30 MPa & $0.13-0.142$ & Insulator \\
\hline Fiber (Kevlar) & 3620MPa & 0.04 & Insulator \\
\hline
\end{tabular}

Kuilla T, Bhadra S, Yaoa D, Kim NH, Bose S and Leea JH 2010 Recent advances in graphene based polymer composites Progress in Polymer Science 35 pp 1350-135 


\section{Applications \& Markets}
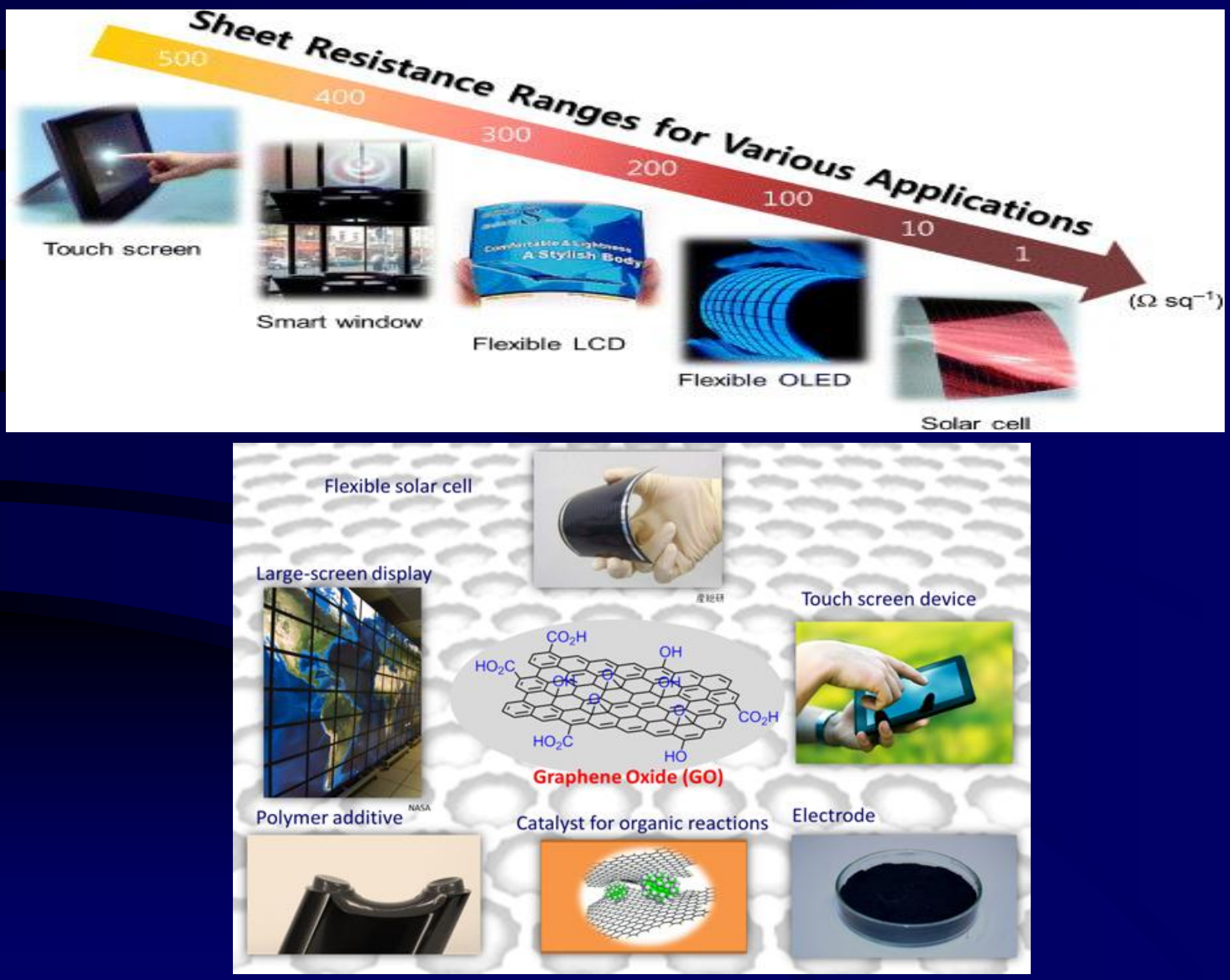


\section{Applications \& Markets}

3 Polymer Fillers

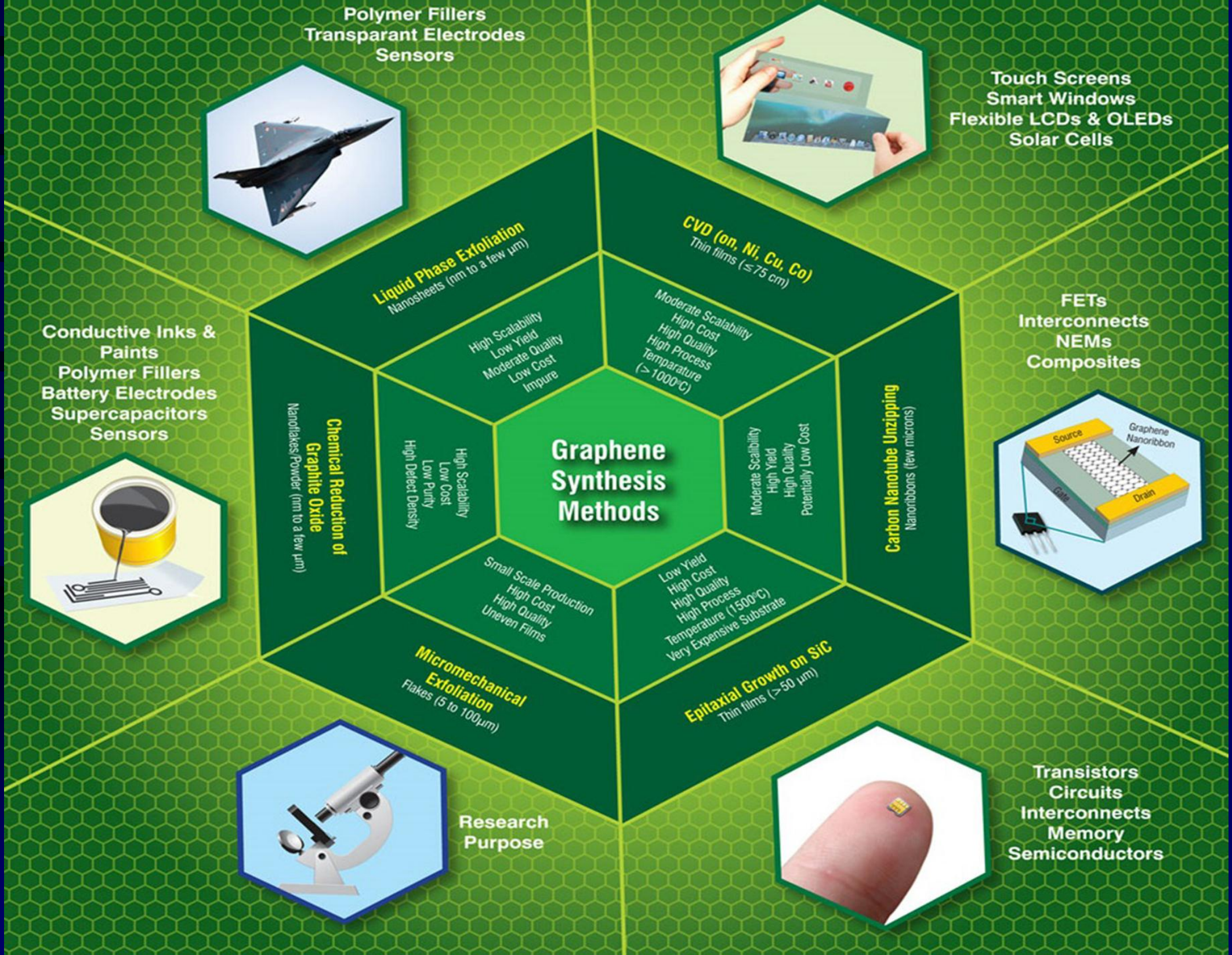




\section{Synthesis methods of Graphene}

(i) Chemical vapour deposition (CVD)

(ii) Micromechanical exfoliation of graphite

(iii) Epitaxial growth on electrically insulating surfaces, such as SiC

(iv) Solution-based reduction of GO

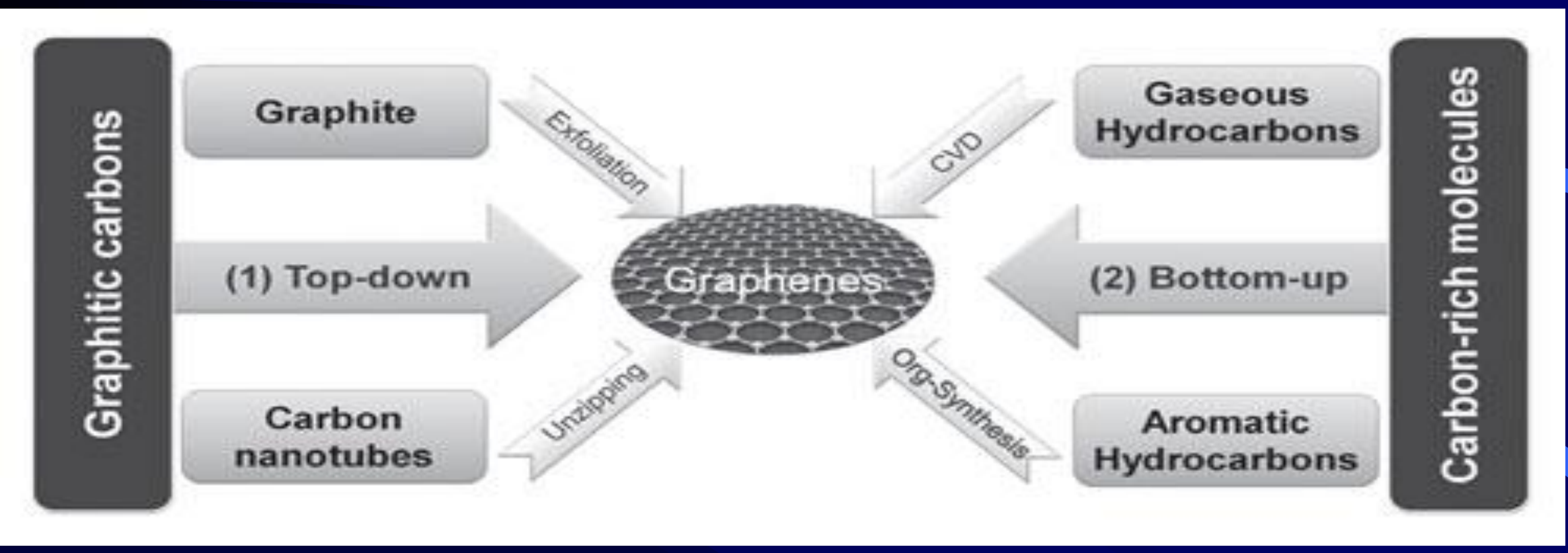

\section{Current synthesis method of Graphene}

- Continuous running underwater Arc-Discharge technique 


\section{Materials required for Arc-discharge method}

- Carbon metal electrodes of research grade graphite (M/s Schurtz Carbon Electrodes Pvt. Ltd., Gandhinagar, Gujarat, India).

- Tungsten, carbon and copper metal electrodes (scrap materials)

- DM water was used as a continuous medium

- Ice-bath for continuous cooling purpose

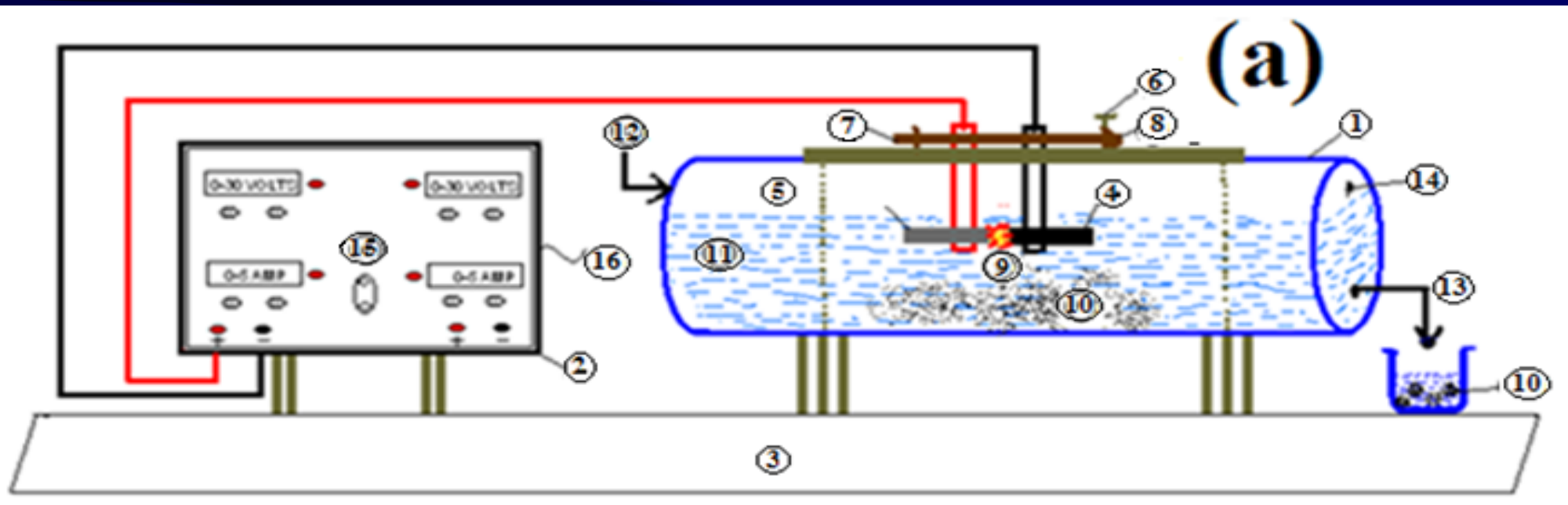

CONTINUOUS RUNNING UNDERWATER ARC-DISCHARGE SET UP

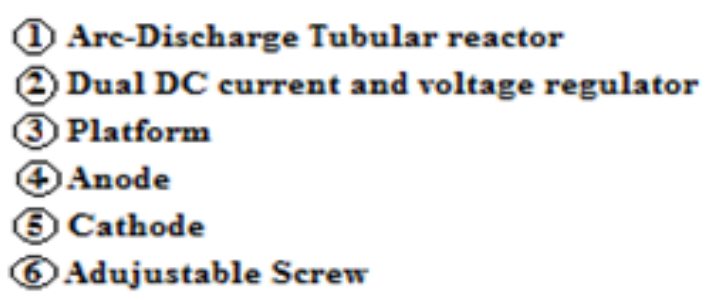

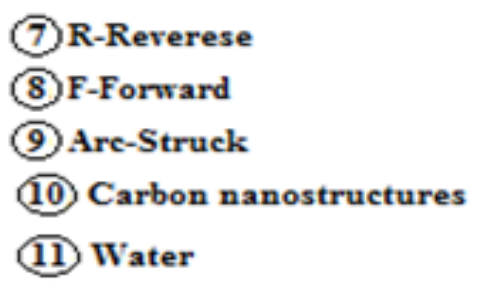

(7) R-Reverese

(8)F-Forward

(10) Carbon nanostructures

(11) Water
(12) Water In
(13) Water Out
(14) Vent
(15) ON-OFF switch
(16) Cable supply

(a) Schematic representation of experiment setup

Shimpi NG, Mishra S, Hansora DP and Savdekar U 2013 Indian Patent 3179/MUM/2013 published online. 


\section{Experimental}

\section{Experimental set up of Batch process}

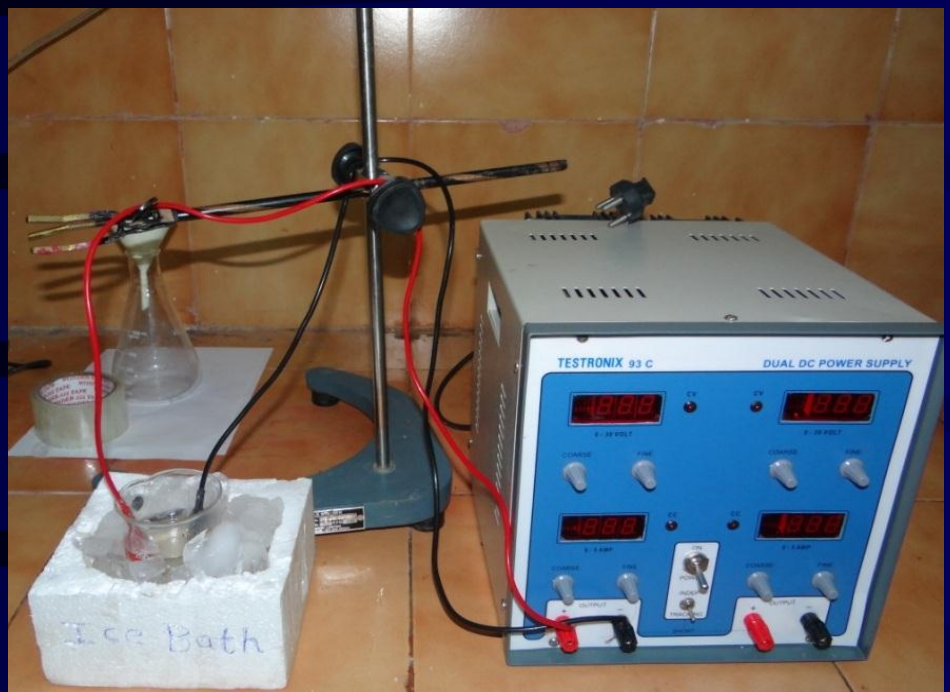

Batch Experimental set up

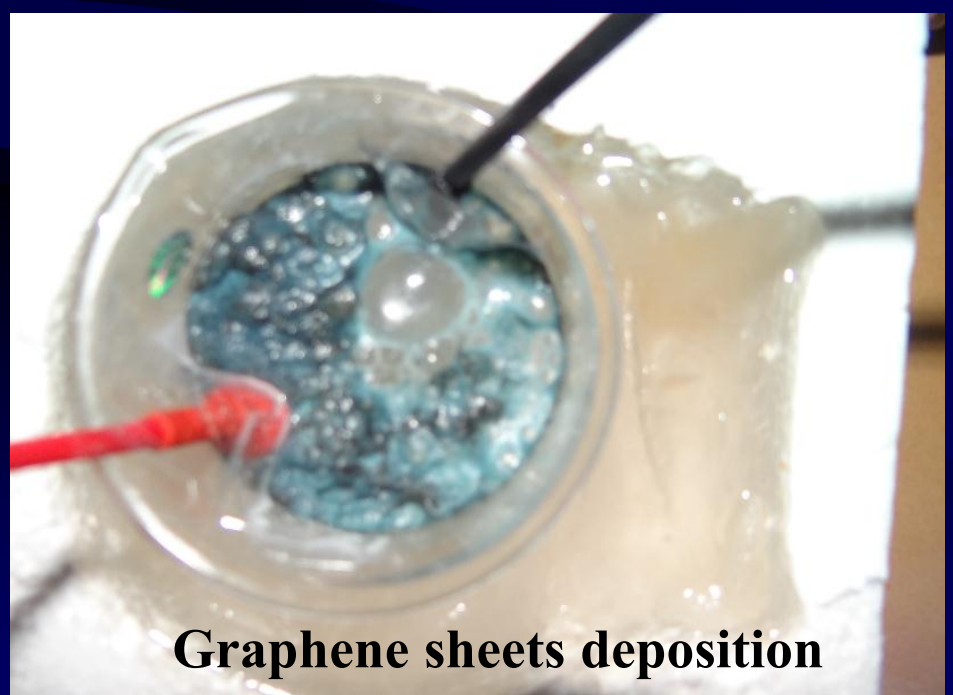

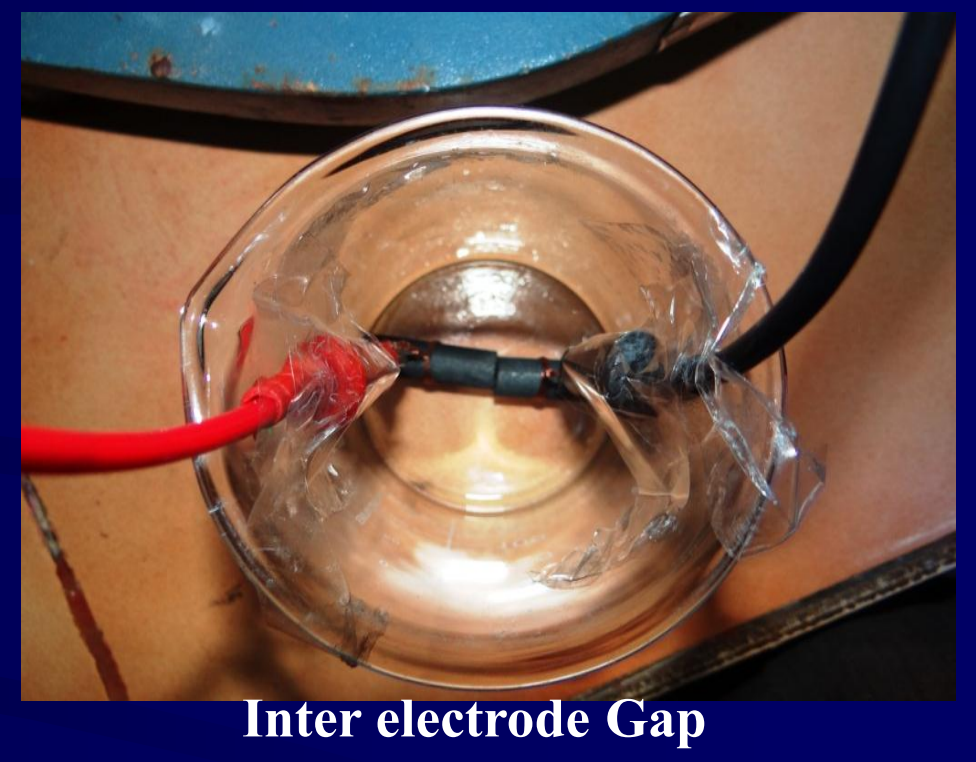

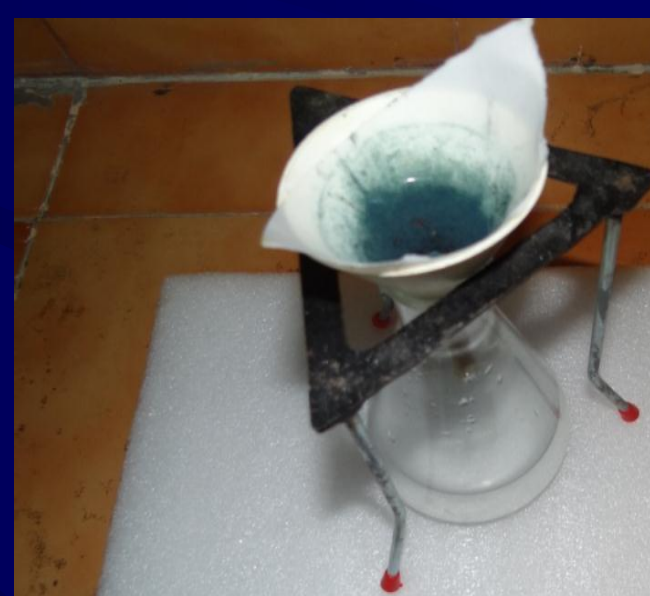

Filtration using filter paper

Shimpi NG, Mishra S, Hansora DP and Savdekar U 2013 Indian Patent 3179/MUM/2013 published online. 


\section{Experimental set up of continuous process}
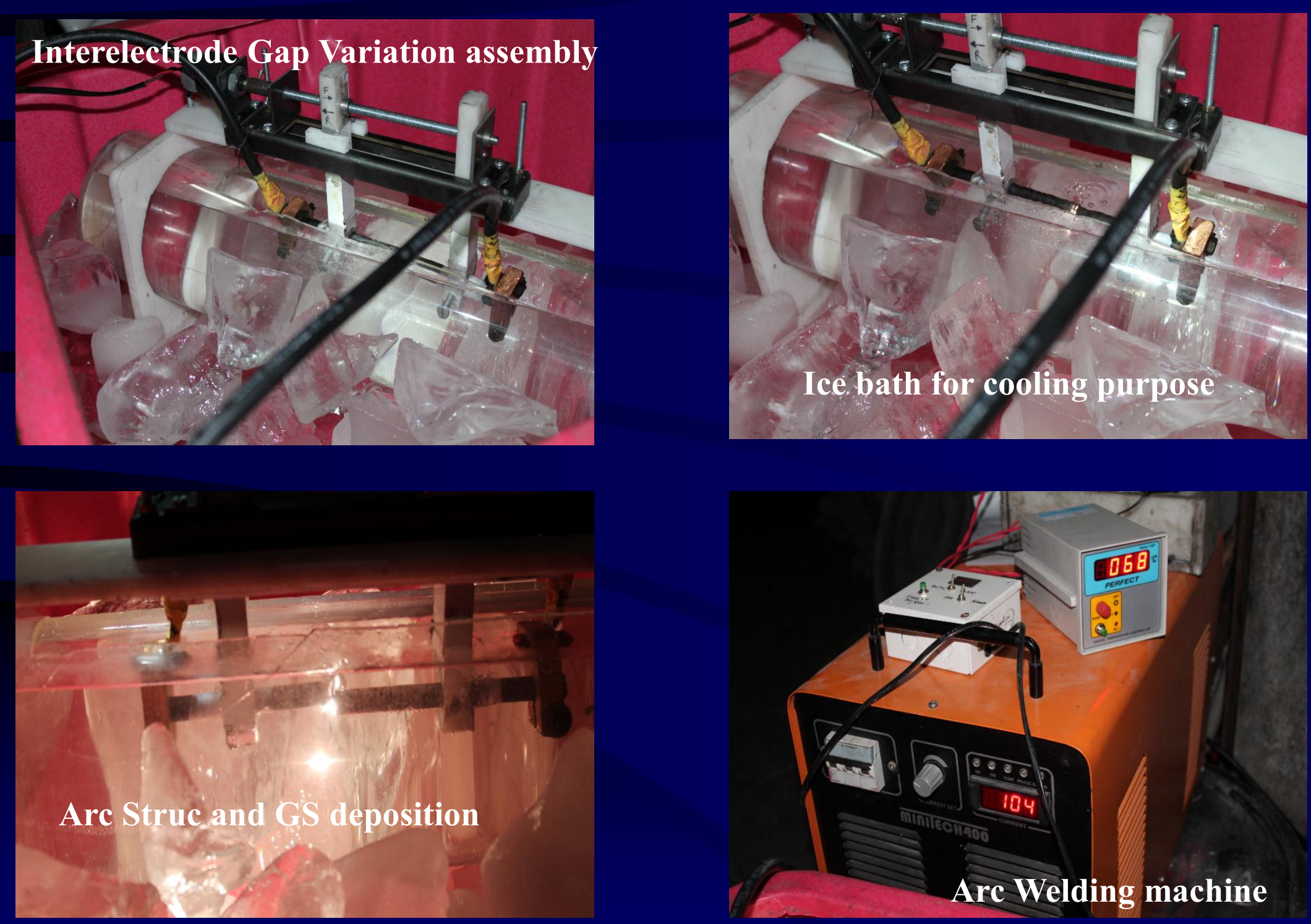

Shimpi NG, Mishra S, Hansora DP and Savdekar U 2013 Indian Patent 3179/MUM/2013 published online. 
 \\ Experimental}

\section{Arc-struc and carbon deposition}

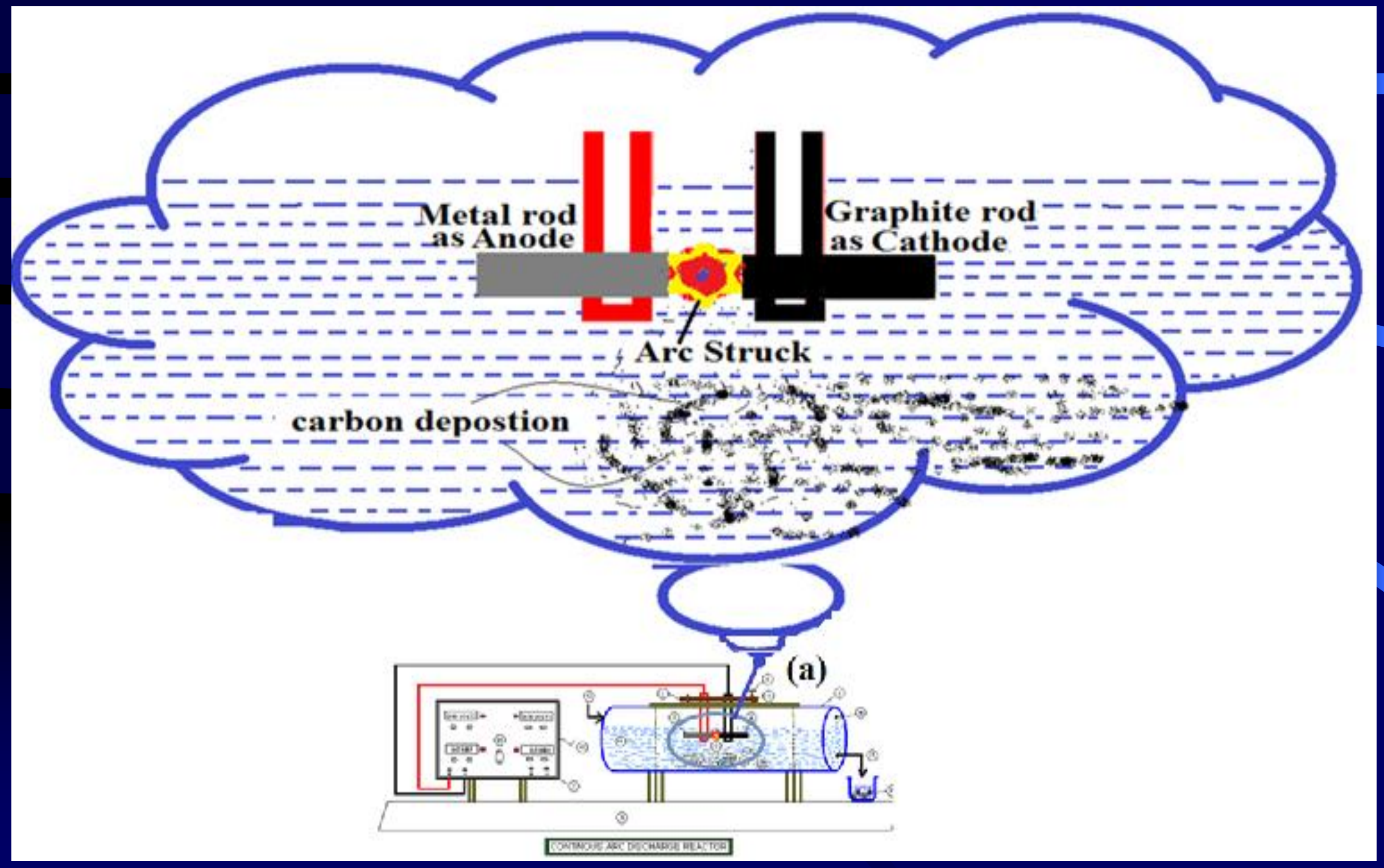




\section{Experimental}

Schematic view
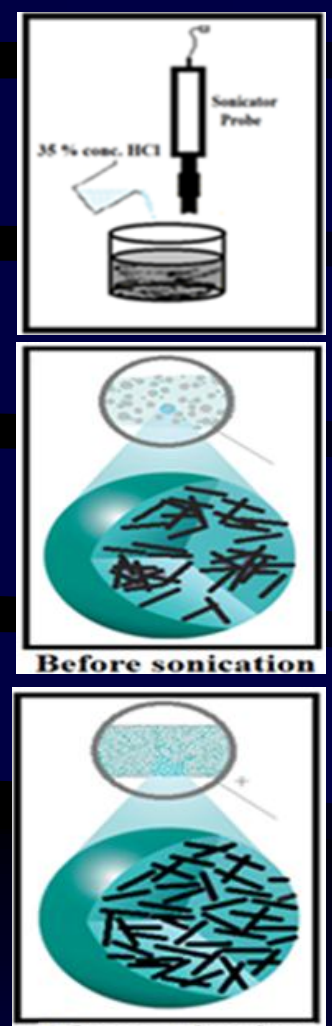

After sonication
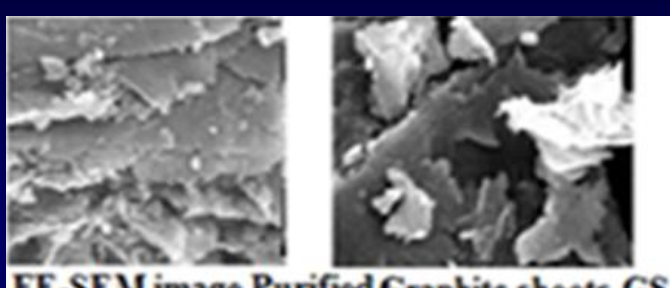

Purification steps

GS $+35 \%$ conc. $\mathrm{HCl}+30 \mathrm{~min}$. Sonication
Separation using filter-paper to remove catalyst particles

3 times Ultra-centrifugation with DM water @ 5000 rpm for $10 \mathrm{~min}$

Second time sonication with $35 \%$ conc. $\mathrm{HCl}$ for $30 \mathrm{~min}$.

3 times Ultra-centrifugation with DM water @ $\mathbf{5 0 0 0}$ rpm for $10 \mathrm{~min}$

Drying in oven @ $180{ }^{\circ} \mathrm{C}$ for 12 hours
Photographic view
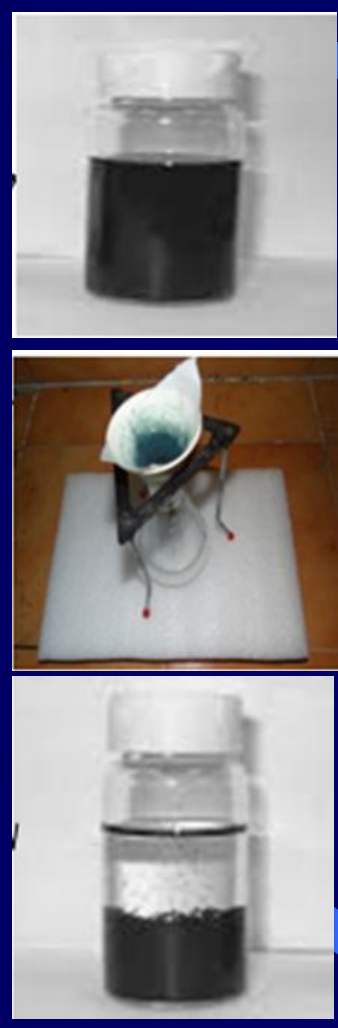

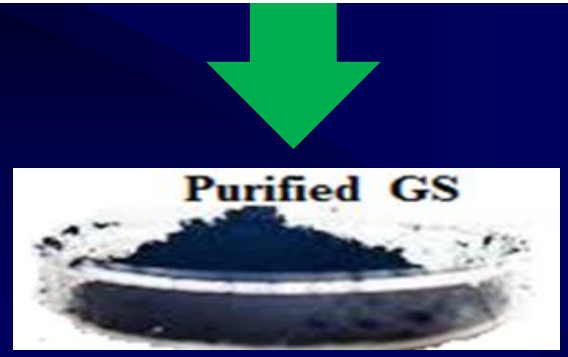

Schematic cum photographic representation of purification steps 


\section{Results}

\section{Obtained vield obtained by continuous process}

\begin{tabular}{|l|l|l|l|l|}
\hline $\begin{array}{l}\text { Sr. } \\
\text { No. }\end{array}$ & $\begin{array}{l}\text { Material uses as } \\
\text { Cathode-Anode }\end{array}$ & $\begin{array}{l}\text { Arc struc } \\
\text { Time }\end{array}$ & $\begin{array}{l}\text { Yield in } \\
\mathrm{gm}\end{array}$ & $\begin{array}{l}\text { Type of structure } \\
\text { obtained }\end{array}$ \\
\hline 1 & Carbon-carbon & $120 \mathrm{~min}$ & 6.2 & $\begin{array}{l}\text { Stacked graphene } \\
\text { nanosheets }\end{array}$ \\
\hline 2 & Carbon-copper & $120 \mathrm{~min}$ & 2.8 & $\begin{array}{l}\text { Tubules wrapped } \\
\text { graphene sheets }\end{array}$ \\
\hline 3 & Carbon-tungston & $120 \mathrm{~min}$ & 2.2 & $\begin{array}{l}\text { Stacked graphene } \\
\text { nanosheets }\end{array}$ \\
\hline
\end{tabular}




\section{Characterization}

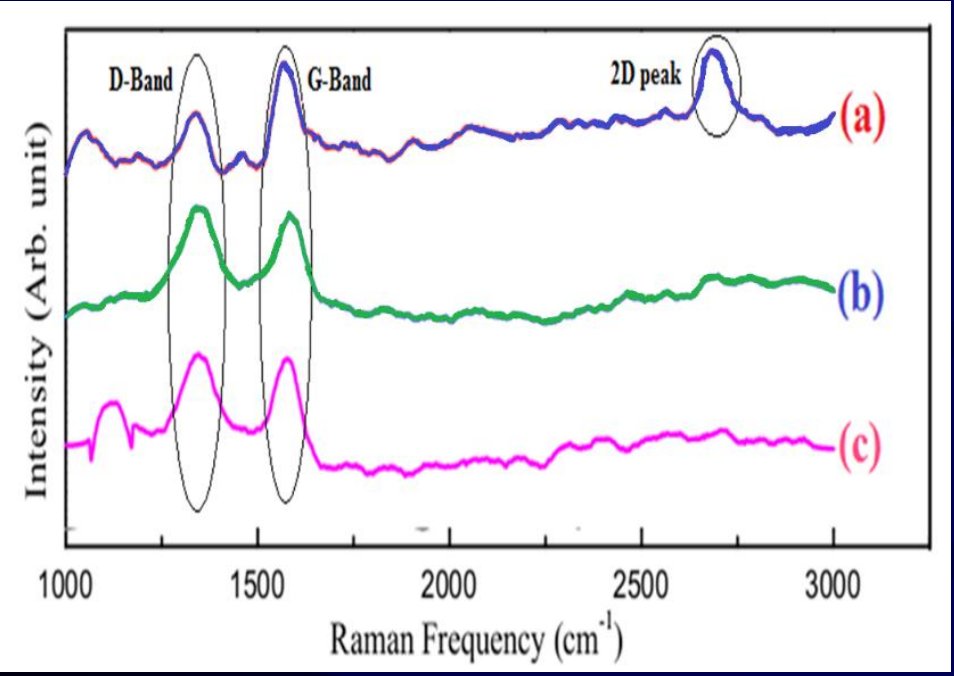

Raman spectra of arc-struck deposits using electrodes (a) carbon-carbon (b) carbon-copper and (c) carbon-tungsten

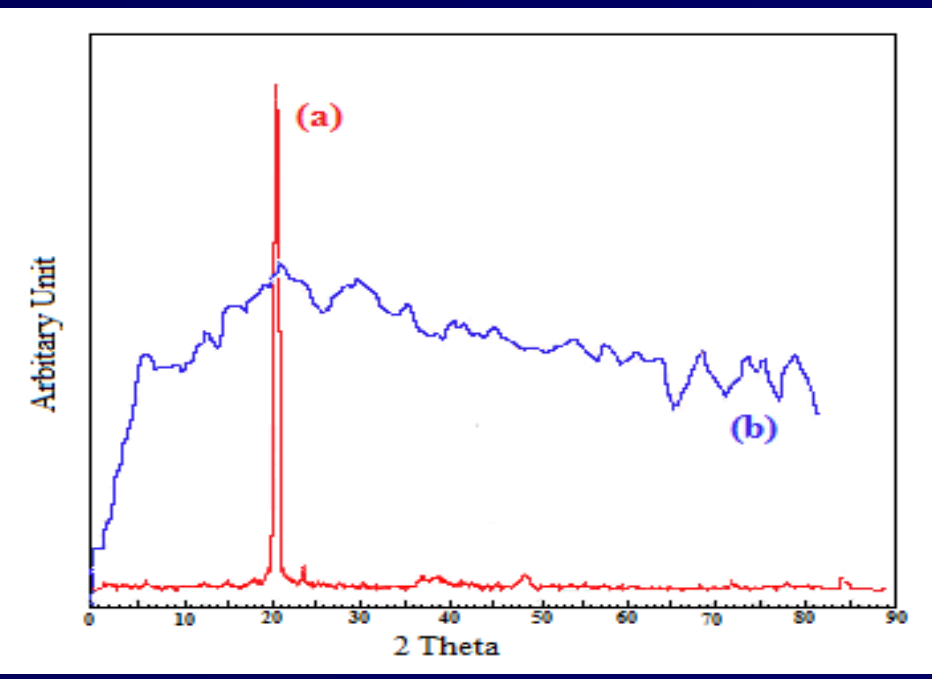

XRD of (a) graphite and (b) graphitic carbon nanosheets

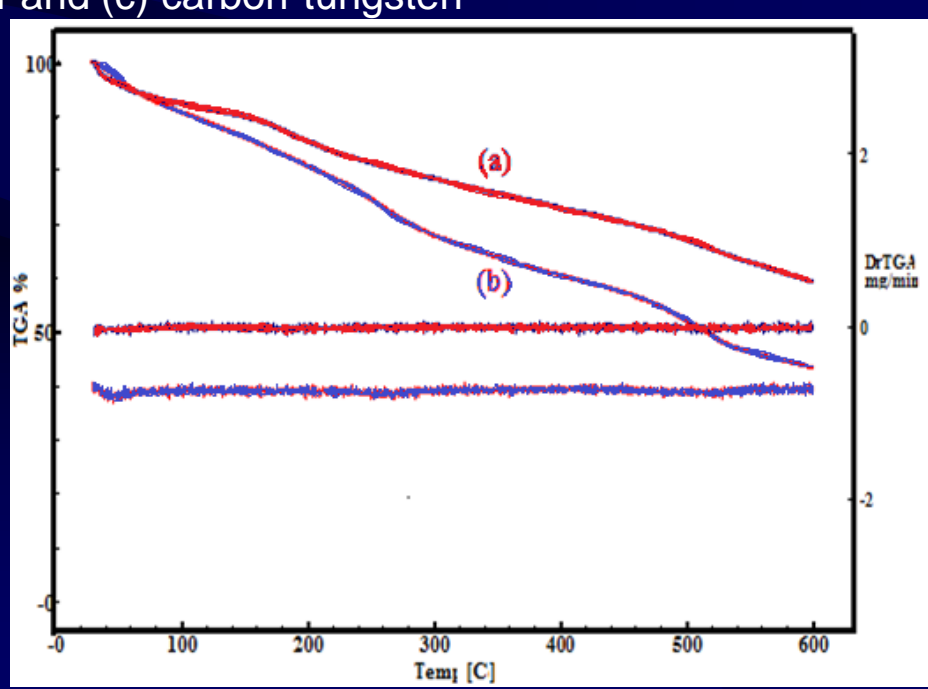

TGA \& DTG images (a) graphite and (b) graphitic carbon sheet 


\section{Characterization}

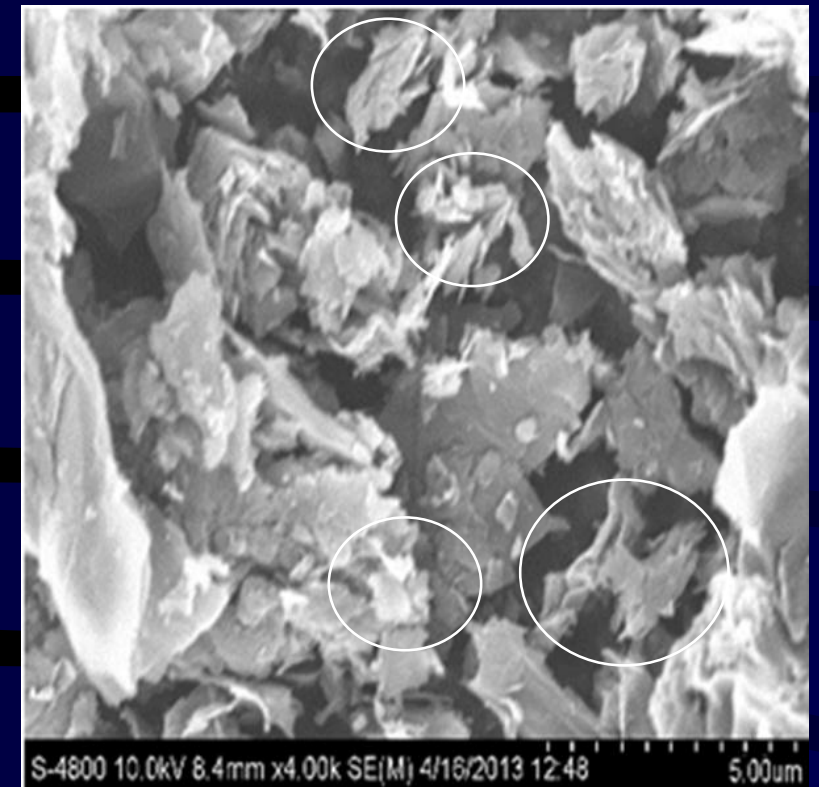

(a) carbon-carbon

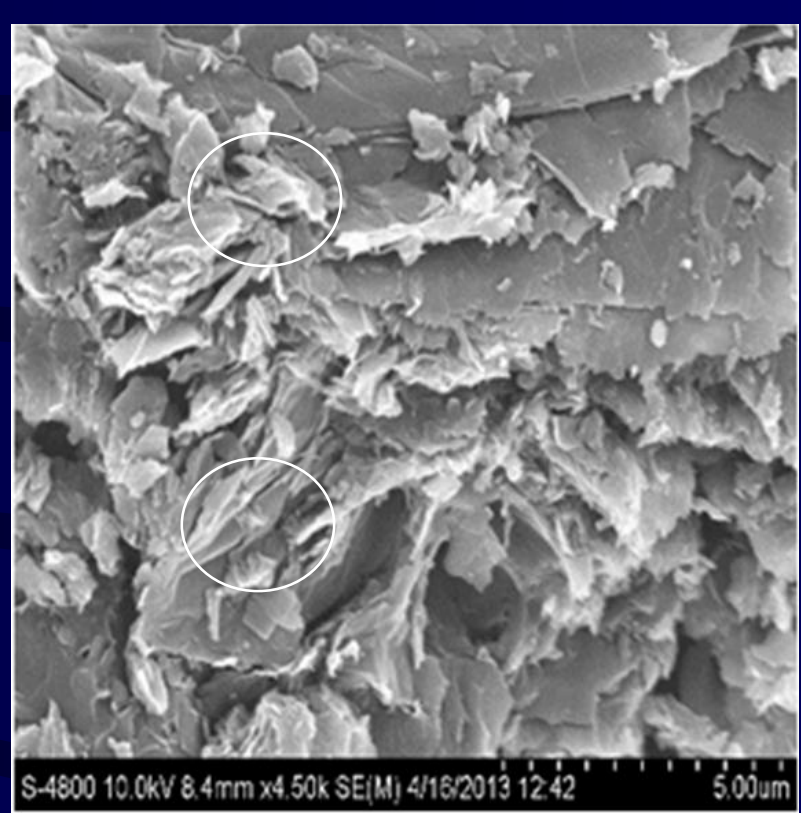

(b) carbon-copper

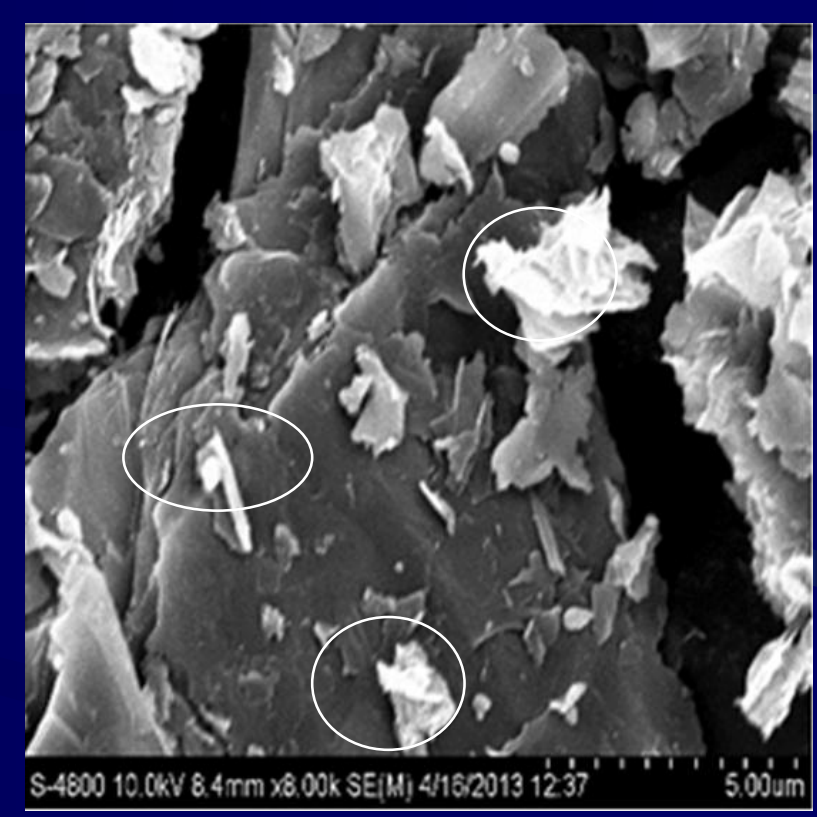

(c) carbon-tungsten

FE-SEM micrographs showing comparison between the microstructure of at different resolution 


\section{Characterization}

(a) carbon-carbon
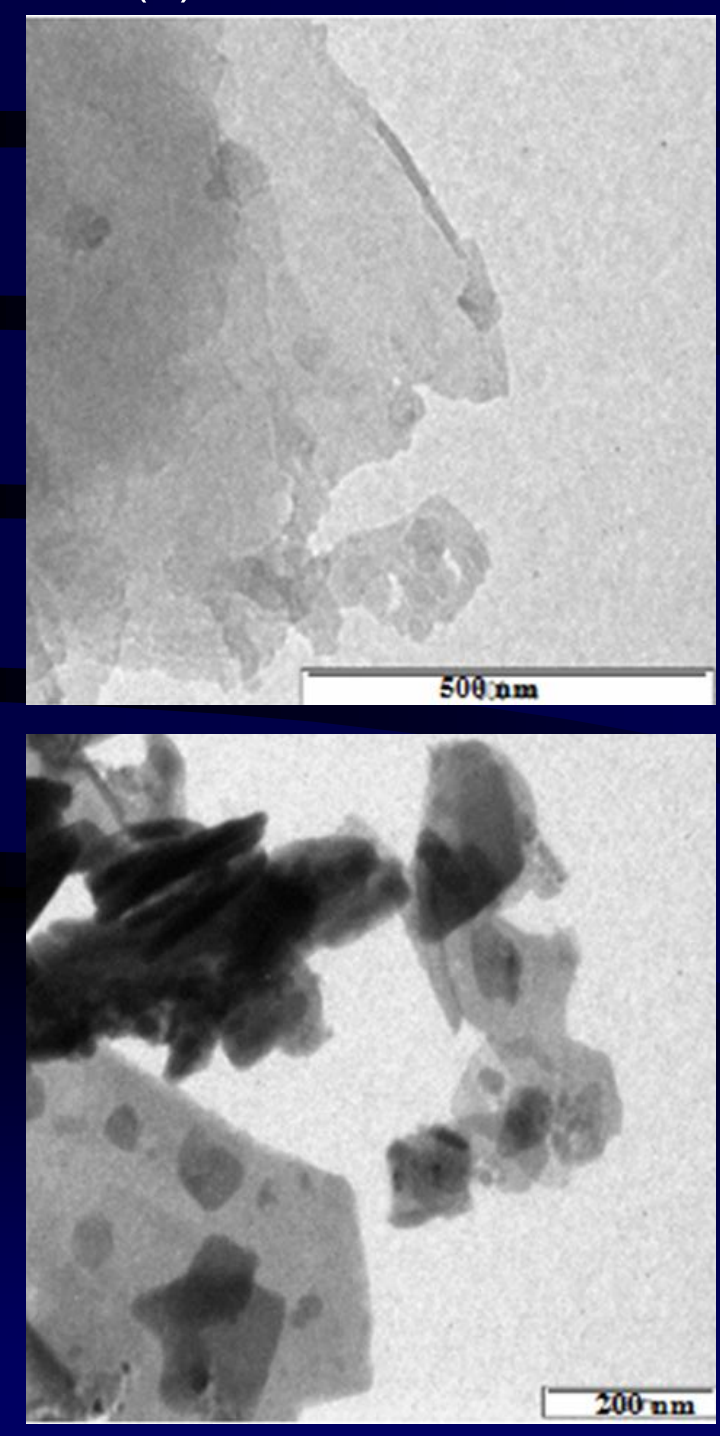

(b) carbon-copper
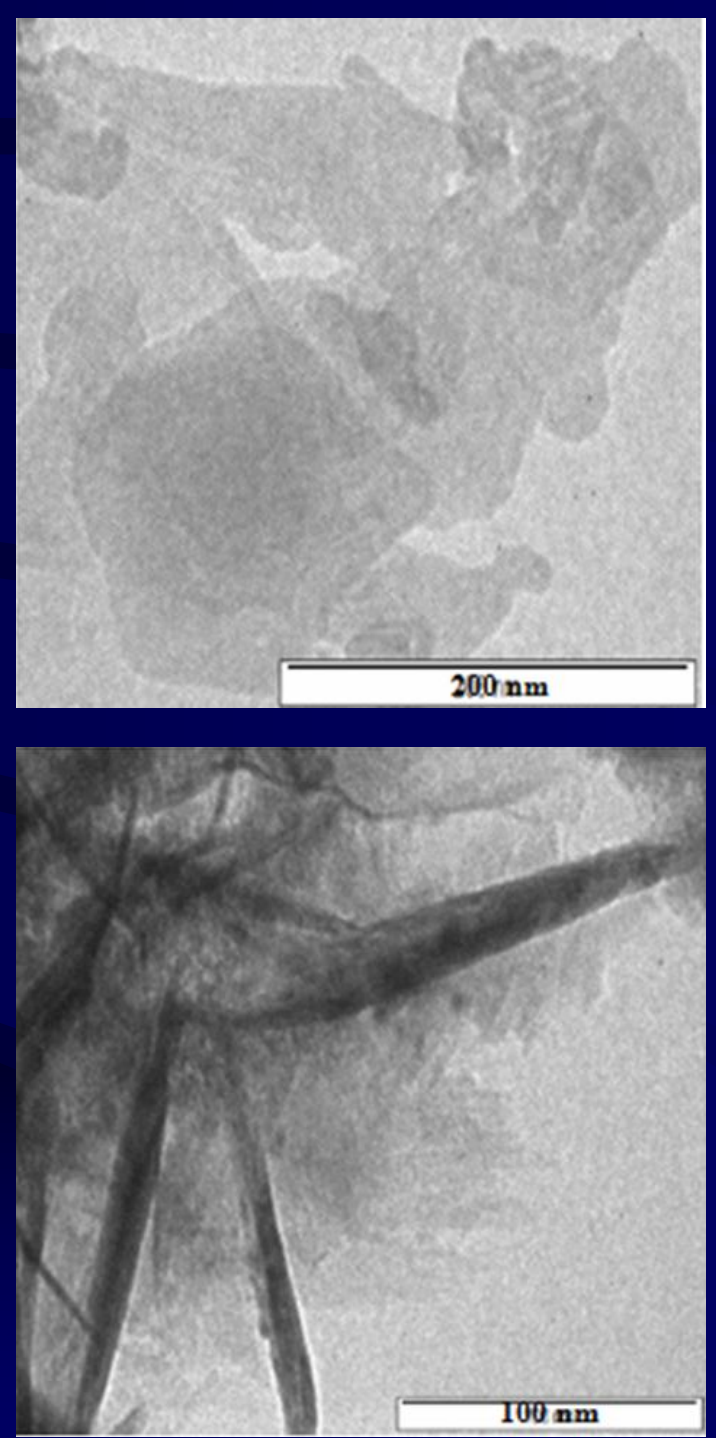

(c) carbon-tungsten
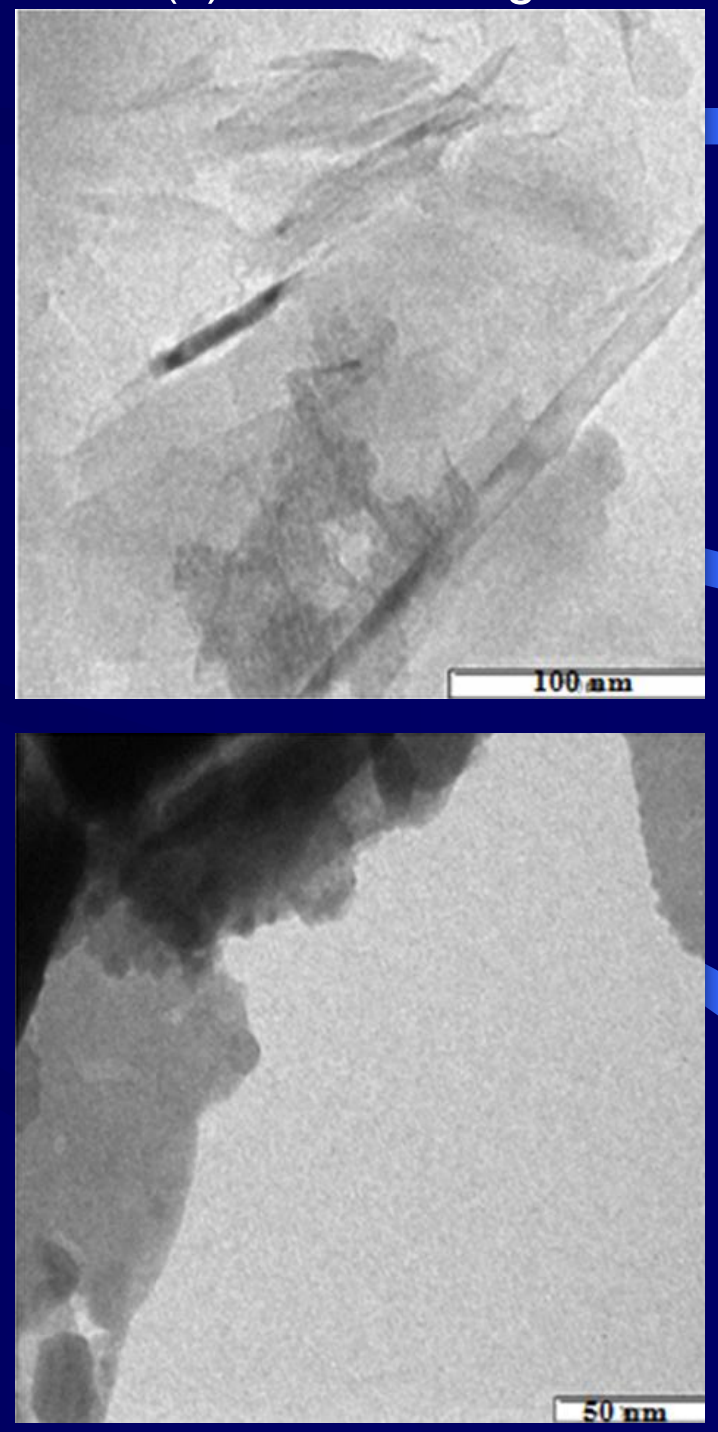

TEM micrographs of graphene sheets at different resolution 


\section{Possible Functionalization}

- Research on graphene has progressed to second generation graphenebased materials that can be divided into two main categories:

1. Chemically modified graphene (CMG): i.e. graphene sheets where carbon atoms are replaced by other atoms (N, B, S, P) or entire functional groups;

2. 3D graphene architectures (3DG): i.e. systems constituted by graphene or CMG sheets assembled together to form 3D interconnected networks or very highly complex nano-objects like hollow nanospheres, crumpled paper, and capsules.

- Surface modification of graphene

The general approaches for preparing organo-modified graphene are

1. Chemical modification,

2. Reduction of GO in a stabilization medium,

3. Covalent modification of graphene,

4. Non-covalent functionalization of graphene,

5. Nucleophilic substitution and

6. Diazonium salt coupling.

- Electrochemical modification of graphene

- $\pi-\pi$ interaction

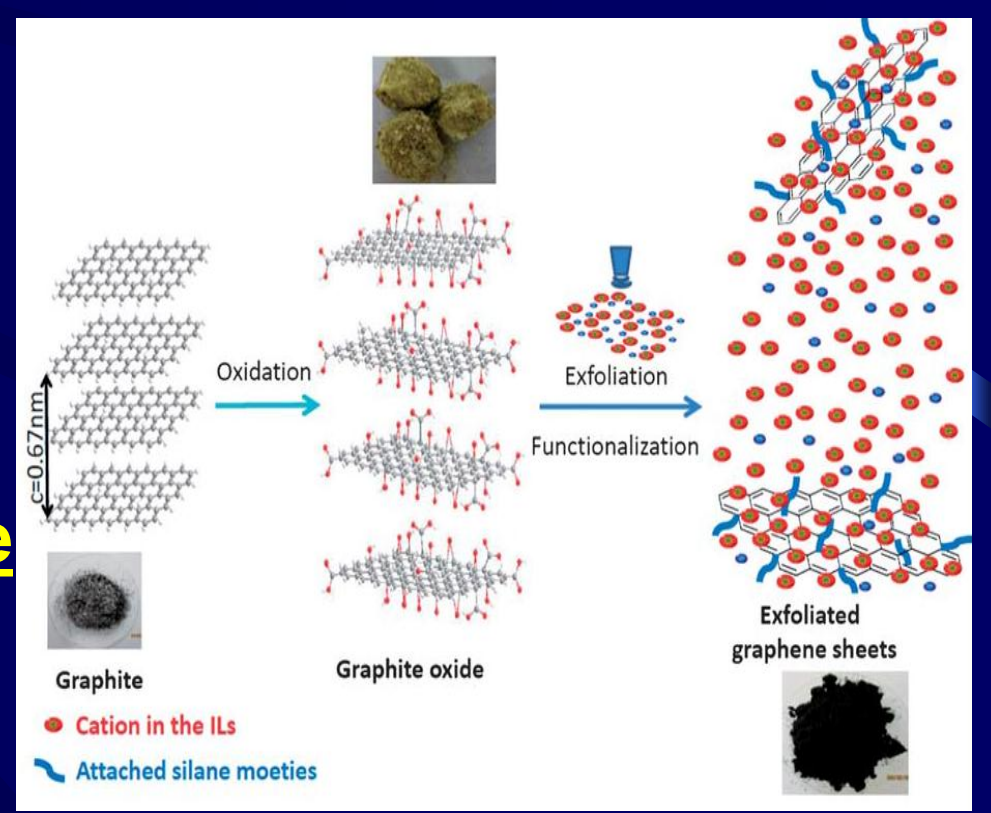




\section{Conclusions}

- This review endeavors to sum up the current status on different graphene derivatives including doped graphene, edge-functionalized graphene nanoribbons, oxidized graphene, hydrogenated and fluorinated graphene, graphyne, graphdiyne, porous graphene and graphone.

- Quantitatively and considerable cost effective yield of carbon nanostructured \& nanocrystalline materials graphitic sheets are obtained by facile, cheapest, simple, and continuous running underwater arc-discharge method.

- It also shows a possibility of enhanced mass production of carbon nanostructured materials. In its basic form, the method requires only a DC power supply, metal-graphite electrode, with no need for pumps, seals, water-cooled vacuum chambers, or purge-gas handling systems.

- The system is easily adaptable to produce large quantities of nanotubes continuously without interruptions for electrode replacement, chamber cleaning, or gas purging. Arcdischarge technique is most suitable, cheaper \& easier to implement for industrial-scale production due to its superior controllability and scalability for fasclilating an efficient formation of graphitic nanosheets.

- It can be shown that graphene demonstrates at best its potential as a technological material whenever good electronic conduction, easy functionalization and a versatile nanodesign are necessary, e.g. in fuel cell electrodes, supercapacitors and batteries. 


\section{Research Group}

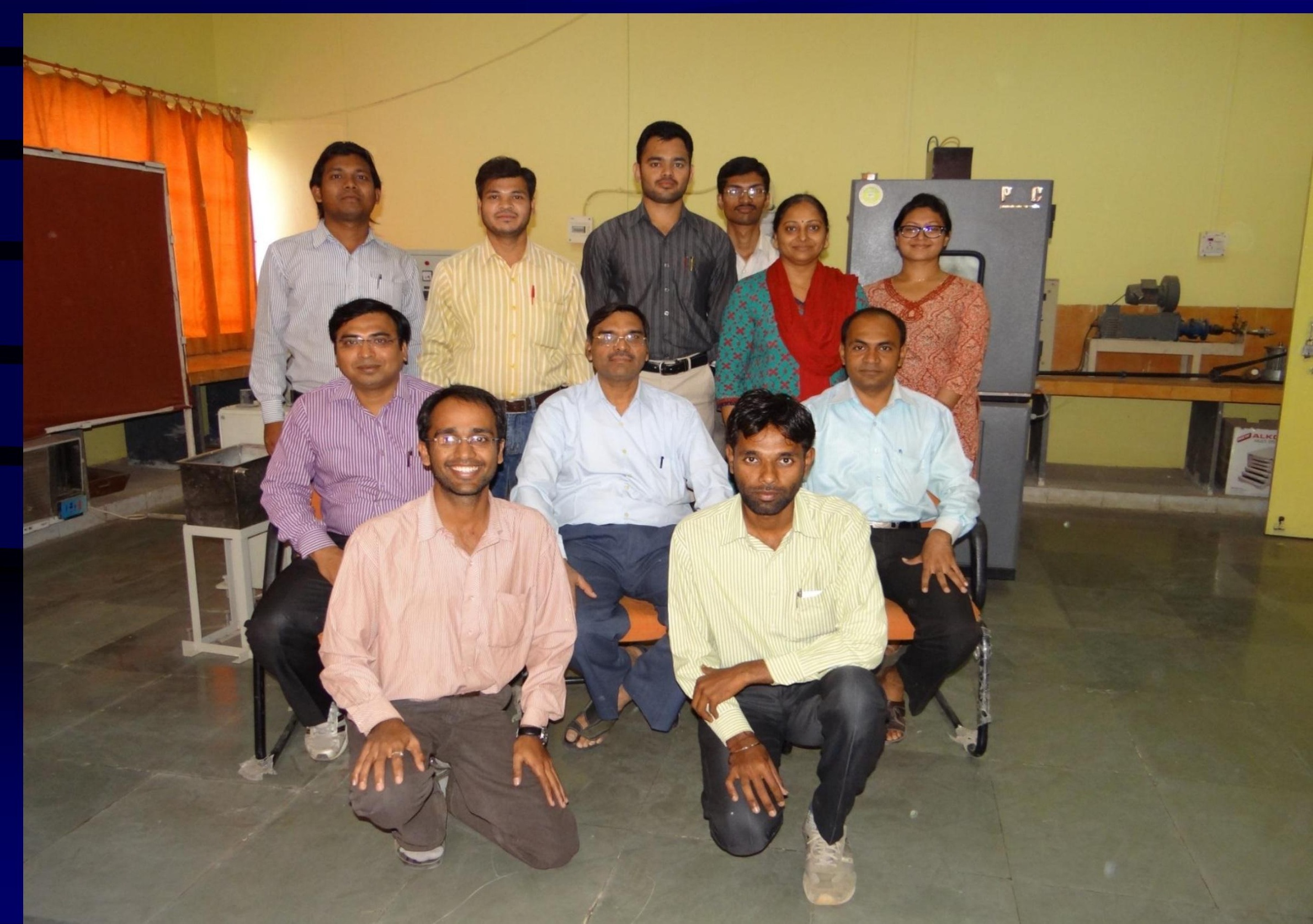


